\title{
Mg2+-Dependent Methyl Transfer by a Knotted Protein: A Molecular Dynamics Simulation and Quantum Mechanics Study
}

Agata P Perlinska

University of Warsaw

Marcin Kalek

University of Warsaw

Thomas Christian

Thomas Jefferson University

Ya-Ming Hou

Thomas Jefferson University

Follow this and additional works at: https://jdc.jefferson.edu/bmpfp Joanna I Sulkowska

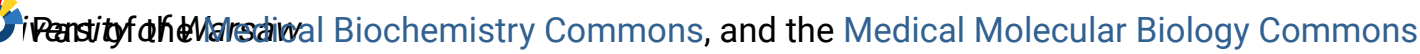
Let us know how access to this document benefits you

\section{Recommended Citation}

Perlinska, Agata P; Kalek, Marcin; Christian, Thomas; Hou, Ya-Ming; and Sulkowska, Joanna I, "Mg2+-Dependent Methyl Transfer by a Knotted Protein: A Molecular Dynamics Simulation and Quantum Mechanics Study" (2020). Department of Biochemistry and Molecular Biology Faculty Papers. Paper 172.

https://jdc.jefferson.edu/bmpfp/172

This Article is brought to you for free and open access by the Jefferson Digital Commons. The Jefferson Digital Commons is a service of Thomas Jefferson University's Center for Teaching and Learning (CTL). The Commons is a showcase for Jefferson books and journals, peer-reviewed scholarly publications, unique historical collections from the University archives, and teaching tools. The Jefferson Digital Commons allows researchers and interested readers anywhere in the world to learn about and keep up to date with Jefferson scholarship. This article has been accepted for inclusion in Department of Biochemistry and Molecular Biology Faculty Papers by an authorized administrator of the Jefferson Digital Commons. For more information, please contact: JeffersonDigitalCommons@jefferson.edu. 


\title{
$\mathrm{Mg}^{2+}$-Dependent Methyl Transfer by a Knotted Protein: A Molecular Dynamics Simulation and Quantum Mechanics Study
}

\author{
Agata P. Perlinska, Marcin Kalek,* Thomas Christian, Ya-Ming Hou,* and Joanna I. Sulkowska* \\ Cite This: ACS Catal. 2020, 10, 8058-8068 \\ Read Online
}

ABSTRACT: $\mathrm{Mg}^{2+}$ is required for the catalytic activity of $\operatorname{TrmD}$, a bacteriaspecific methyltransferase that is made up of a protein topological knot-fold, to synthesize methylated $\mathrm{m}^{1} \mathrm{G} 37-\mathrm{tRNA}$ to support life. However, neither the location of $\mathrm{Mg}^{2+}$ in the structure of TrmD nor its role in the catalytic mechanism is known. Using molecular dynamics (MD) simulations, we identify a plausible $\mathrm{Mg}^{2+}$ binding pocket within the active site of the enzyme, wherein the ion is coordinated by two aspartates and a glutamate. In this position, $\mathrm{Mg}^{2+}$ additionally interacts with the carboxylate of a methyl donor cofactor S-adenosylmethionine (SAM). The computational results are validated by experimental mutation studies, which demonstrate the importance of the $\mathrm{Mg}^{2+}$-binding residues for the catalytic activity. The presence of $\mathrm{Mg}^{2+}$ in the binding pocket induces SAM to adopt a unique bent shape required for the methyl transfer activity and causes a structural reorganization of the active site. Quantum mechanical calculations show that the

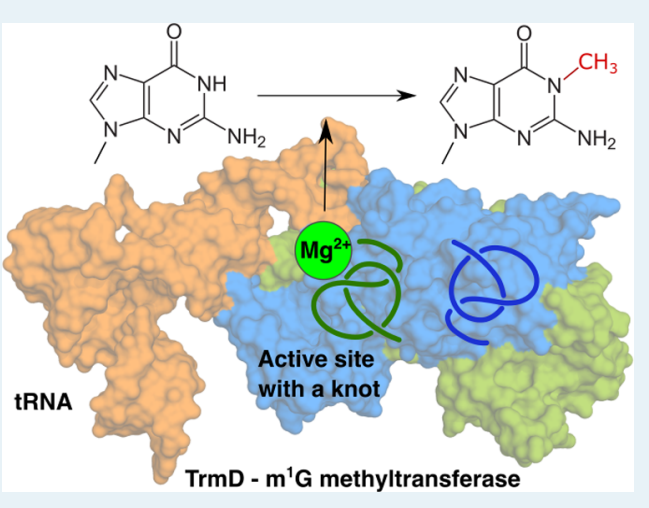
methyl transfer is energetically feasible only when $\mathrm{Mg}^{2+}$ is bound in the position revealed by the MD simulations, demonstrating that its function is to align the active site residues within the topological knot-fold in a geometry optimal for catalysis. The obtained insights provide the opportunity for developing a strategy of antibacterial drug discovery based on targeting of $\mathrm{Mg}^{2+}$-binding to TrmD.

KEYWORDS: $\mathrm{Mg}^{2+}$ binding, trefoil knot, methyl transfer, $\mathrm{m}^{1}$ G37-tRNA, enzymatic catalysis

\section{INTRODUCTION}

Methyl transfer reactions play vital roles in a variety of physiological processes. They most often employ the methyl donor S-adenosyl-methionine (SAM) for methyl transfer. The methyl group of SAM is a part of the charged sulfonium moiety, which is thermodynamically labile, making the methyl substituent highly reactive toward nucleophiles. As such, methyl transfers catalyzed by methyltransferases usually occur without the assistance of metal ions. Even in the rare cases, wherein metal ions are required, their role is usually limited to stabilizing substrates and enhancing selectivity, ${ }^{1-4}$ but are not directly involved in the actual breaking and formation of chemical bonds. This is in contrast to, for instance, phosphoryl transfer reactions catalyzed by kinases, which strictly require divalent metal ions to orient the $\gamma$-phosphoryl group of ATP "in-line" with respect to the substrate to create the correct geometry for catalysis. ${ }^{5}$

Unexpectedly, it has recently been shown that the SAMdependent methyl transfer catalyzed by a bacterial methyltransferase TrmD requires the presence of $\mathrm{Mg}^{2+}$ ions. ${ }^{6}$ This reaction produces $\mathrm{m}^{1} \mathrm{G} 37$-tRNA, which maintains protein synthesis reading frame and thus is essential for life. ${ }^{7-10}$ While the $\mathrm{m}^{1} \mathrm{G} 37$ methylation of tRNA is strictly conserved in all three domains of life, ${ }^{7,11}$ it is catalyzed by $\operatorname{TrmD}$ in bacteria, but by Trm5 in Archaea and Eukarya. ${ }^{12}$ In contrast to TrmD that requires $\mathrm{Mg}^{2+}$ for catalysis, $\operatorname{Trm} 5$ needs no metal ions, a key distinction that separates the two enzymes, which also differ in sequence, ${ }^{13}$ structure, ${ }^{14-16}$ topology, ${ }^{17}$ SAM binding, ${ }^{18,19}$ and the mechanism of recognition of tRNA and the target base. ${ }^{20,21}$ These fundamental differences, together with the essentiality of the $\mathrm{m}^{1} \mathrm{G} 37$-tRNA product for growth, have placed $\mathrm{TrmD}$ as a leading antimicrobial target. ${ }^{22}$ Additionally, the $\mathrm{Mg}^{2+}$-requirement of TrmD has been recently implicated in regulating the expression of the metal ion transporter gene mgtA ${ }^{23}$ suggesting a broader impact in biology. Therefore, a detailed elucidation of the $\mathrm{Mg}^{2+}$-dependent catalysis of TrmD is of utmost importance, permitting the development of selective targeting of the enzyme, away from Trm5 and the majority of other methyltransferases, which are independent of divalent metal ions for methyl transfer. Indeed, TrmD is present in all of the 12 drug-resistant bacteria recently identified as high-priority pathogens by the World Health Organization. ${ }^{24}$ Although pharmaceutical companies attemp-

Received: January 5, 2020

Revised: June 18, 2020

Published: June 22, 2020 
ted to target $\mathrm{TrmD}$, the progress has stalled ${ }^{25}$ mainly because its catalytic mechanism is not sufficiently understood and the selectivity against Trm5 not adequately addressed.

The $\mathrm{Mg}^{2+}$ requirement of TrmD may be associated with the unusual active site structure of this enzyme. TrmD is a member of the SPOUT family of methyltransferases ${ }^{13,26}$ that feature a knotted active site (part of the protein backbone is threaded through a loop) resulting in a topology known as the "trefoilknot"-fold. $^{27,28}$ The role of knots in the protein structure has recently been a subject of intensive research. ${ }^{29}$ The knots have been shown to, for example, have an impact on protein stability $^{30,31}$ and resistance to degradation. ${ }^{32}$ However, the common presence of knots in enzyme active sites implies a function in the catalytic activity, which is yet to be elucidated. TrmD is an obligate dimer that binds SAM in the deep crevice of the trefoil-knot in between the two monomers. ${ }^{33}$ In contrast, Trm5 is an active monomer and its active site is made up of the open structure of the dinucleotide-binding Rossmann-fold that binds SAM. ${ }^{15}$ TrmD is also unique in that it uses only one $\mathrm{Mg}^{2+}$ ion per dimeric enzyme to activate the methyl transfer reaction. ${ }^{6}$

It has been established that two highly conserved amino acids are required for the activity of TrmD: D169, whose role is most likely to abstract the proton from the $\mathrm{N}^{1}$ of $\mathrm{G} 37$, and R154, which may provide stabilization of the developing negative charge at the $\mathrm{O}^{6}$ (Figure 1). ${ }^{6,12,34,35}$ The $\mathrm{Mg}^{2+}$ -

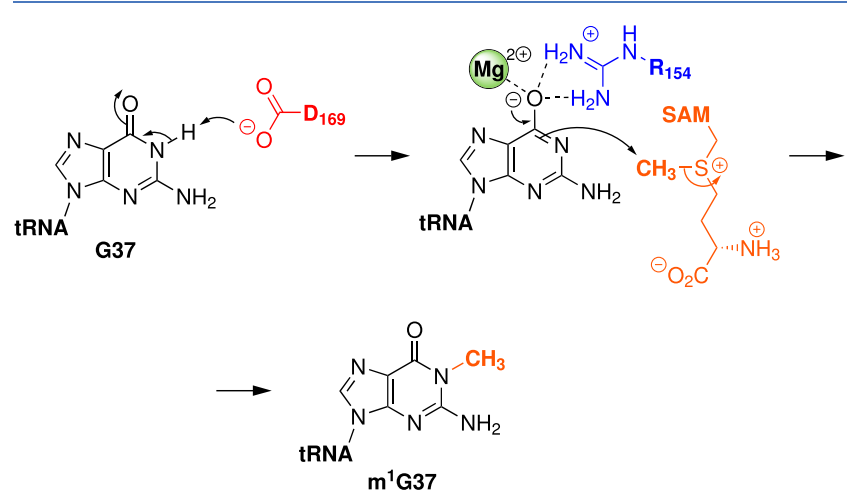

Figure 1. Overview of the originally proposed mechanism of methylation catalyzed by TrmD, postulating the interaction of $\mathrm{Mg}^{2+}$ with the $\mathrm{O}^{6}$ of $\mathrm{G} 37$. $^{6}$

dependent activation is chemically novel and it has been originally proposed that the metal ion is coordinated to the $\mathrm{O}^{6}$ of G37 target nucleobase, in a role similar to that of R154 by acidifying the $\mathrm{N}^{1}$ proton and stabilizing the negatively charged intermediate. ${ }^{6}$ Such mechanistic picture was suggested by metal rescue experiments, which have shown that while TrmD methylates the thio-containing $S^{6}-\mathrm{G} 37$ analog of tRNA with a fourfold reduced efficiency, the replacement of $\mathrm{Mg}^{2+}$ with $\mathrm{Co}^{2+}$ ions in the buffer restores the activity with this modified substrate to a normal level. ${ }^{6}$ Because $\mathrm{Co}^{2+}$ has a high affinity for sulfur, ${ }^{36,37}$ this result suggested the direct interaction of the atom in position 6 of G37 with the metal ion during the transition state of methyl transfer.

However, because none of TrmD crystal structures contain $\mathrm{Mg}^{2+33-35,38}$ to reveal its actual location in the structure of the enzyme, the details of the catalytic mechanism remain unclear. The $\mathrm{Mg}^{2+}$-dependent catalysis is also difficult to study by spectroscopy because the magnesium ion is spectroscopically silent. We believe that computational methods can be efficiently applied to address both the issues of the exact $\mathrm{Mg}^{2+}$ binding position to the enzyme and its role in the catalysis. Thus, herein, we describe a combined molecular dynamics (MD) simulation and quantum mechanics (QM) investigations aimed at elucidating the $\mathrm{Mg}^{2+}$-dependent catalysis by TrmD. While the MD method allows for a comprehensive analysis of the conformational landscape and the preference of the enzyme for $\mathrm{Mg}^{2+}$ binding, the $\mathrm{QM}$ enables the quantitative analysis of the energetics of methyl transfer. Our current computational studies, validated by mutational experiments, uncover a new site for $\mathrm{Mg}^{2+}$ binding within the active site, but away from G37, which was missed previously. These results demonstrate that a primary role of the ion is in fact to optimize the conformations of the active site and of SAM for methyl transfer.

\section{RESULTS AND DISCUSSION}

2.1. MD Simulations. 2.1.1. $\mathrm{Mg}^{2+}$ Preferentially Binds within the Active Site of TrmD. Each monomer of TrmD consists of two domains ( $\mathrm{N}$ - and $\mathrm{C}$-terminal) and a flexible linker between them. The trefoil-knot is embedded in the $\mathrm{N}$ terminal domain (Figure 2). TrmD is distinct from other

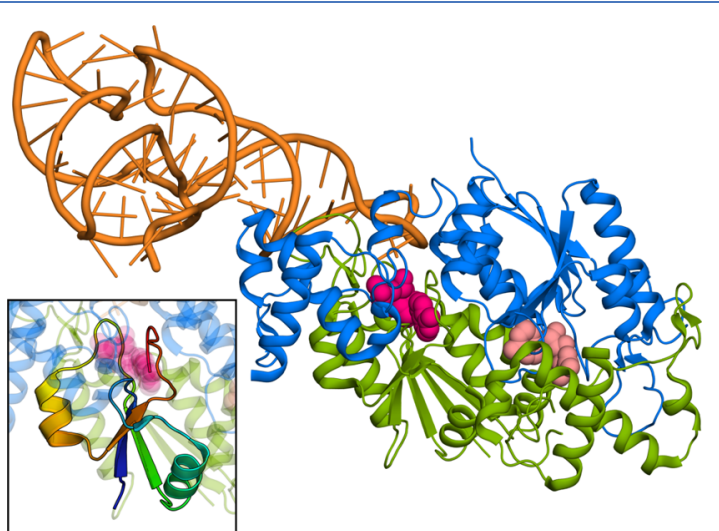

Figure 2. Crystal structure of the ternary TrmD-tRNA-SFG complex (PDB code: 4yvi; SFG = Sinefungin, a potent SAM analog). The inset shows the knotted region of TrmD (in rainbow-traced cartoon representation) and SFG colored magenta and presented in van der Waals representation. The substrate (tRNA) is colored orange, the two chains of the protein are colored blue and green. The location of the knot along the backbone was determined using KnotProt database. ${ }^{14}$

SPOUT methyltransferases in that only one active site is operative at a time and that only one tRNA is bound per dimer, consistent with the finding that only one $\mathrm{Mg}^{2+}$ per dimer is required for catalysis. ${ }^{6}$

Available data concerning the location of $\mathrm{Mg}^{2+}$ in the TrmD complex is limited. Especially there is a lack of structural details regarding the ion's binding. ${ }^{38}$ To thoroughly probe the possible ion binding sites, we used both the classical and the replica exchange all-atom MD simulations, with the latter allowing for a broader probing of the conformational space. Such simulations are the most reliable means to locate the most favorable binding sites of $\mathrm{Mg}^{2+}$ and to determine how the ion binding affects the enzyme structure. The two methods yielded identical results and conclusions, which are summarized in this section (technical details of the simulations are given in the Methods section and in the Supporting Information). 
We performed the simulations based on two forms of Haemophilus influenzae TrmD: the binary complex of the holoenzyme with SAM and the ternary complex of the holoenzyme with SAM and tRNA. Simulations for each complex were performed for almost $7.5 \mu \mathrm{s}$ in 27 independent trajectories of classical MD simulations and additional 6 independent replica exchange trajectories for the ternary complex. $\mathrm{Mg}^{2+}$ ions were placed randomly in the explicit solvent with no contact with the complex at the start of each simulation. Note that beside $\mathrm{Mg}^{2+}$ there were also $\mathrm{Na}^{+}$ions in the simulation system that were used to neutralize the overall charge.

In the simulations, $\mathrm{Mg}^{2+}$ ion binds spontaneously and repeatedly to the active site of both complexes, but at an unexpected position. Namely, instead of coordinating to G37 as proposed before (Figure 1), ${ }^{6}$ the ion interacts with the carboxylates of three acidic residues in the active site-E116, D169*, and D177* (* symbol denotes the residues from the second monomer of TrmD) and also with the carboxylate of SAM (each deprotonated under the physiological $\mathrm{pH}$, Figure 3A). We observed a clear preference for the $\mathrm{Mg}^{2+}$ binding to

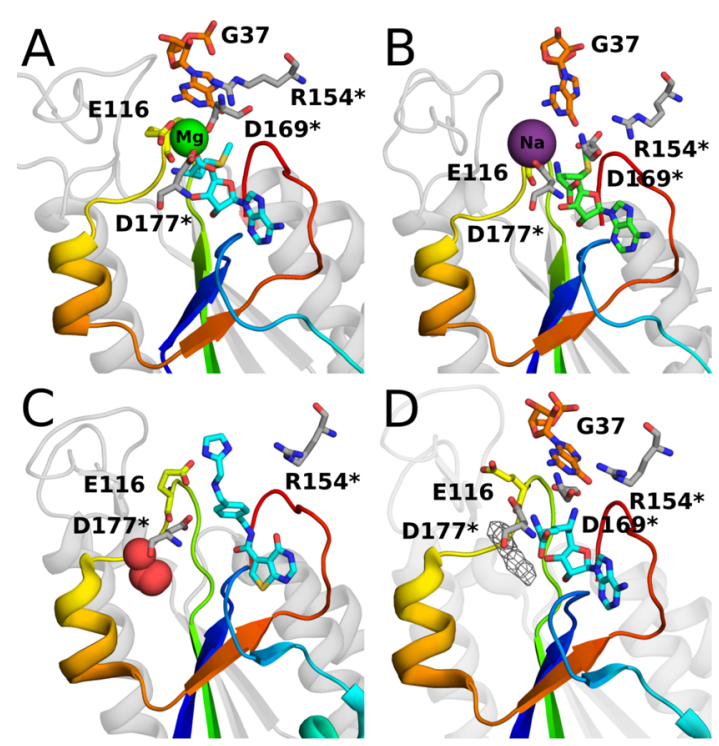

Figure 3. Active site region of TrmD. (A) binding site of $\mathrm{Mg}^{2+}$ ion determined by MD simulations, (B) preferred binding site of $\mathrm{Na}^{+}$ion in simulations without $\mathrm{Mg}^{2+}$, (C) positions of water molecules (from PDB codes: 4mcb, 4yq0, 4yq6, 4yqo) having more than four interactions in crystal structures of TrmD (putatively ions), (D) fragment of electron density map (FoFc, 3 sigma, PDB code: 4yvi) showing an unassigned density in the same region. Rainbow-traced cartoon representation shows the knotted region of $\operatorname{TrmD}$.

only one of the two active sites (Figure S1), supporting the notion that only one metal ion is required for catalysis. ${ }^{6}$ Upon binding of $\mathrm{Mg}^{2+}$ to one site, the interdomain linker becomes stabilized in the position that blocks the ion from access to the second potential ion binding site (Figure S5). The fact that both the binary and ternary complexes have the same binding mode of $\mathrm{Mg}^{2+}$ shows that the ion does not require the presence of tRNA for binding to TrmD, also in line with the experimental results. It is worth noting that the starting structure of the binary complex was symmetrical and we observe unbiased binding of the ion occurring at either one of the active sites, which shows the robustness of the applied computational approach.
Although we performed long and extensive simulations, we did not observe a spontaneous binding of $\mathrm{Mg}^{2+}$ to nucleobase G37. In the case when we manually placed $\mathrm{Mg}^{2+}$ near the $\mathrm{O}^{6}$ of G37 (10 independent simulations), the ion immediately moved away (within an average of $10 \mathrm{~ns}$ ) from the $\mathrm{O}^{6}$ to make contact with the $\mathrm{N}^{7}$ of G37 instead. Even during this short period, we often observed a spontaneous binding of a $\mathrm{Na}^{+}$ion in the same negatively charged binding pocket comprised of the carboxylate groups of E116, D169*, D177*, and SAM, resulting in a temporary enzyme structure containing two metal ions bound simultaneously.

Furthermore, we performed similar simulations of TrmD complexes, but under conditions without $\mathrm{Mg}^{2+}$, in which $\mathrm{Na}^{+}$ were the only positively charged ions present in the solvent. We observed that, while the monovalent $\mathrm{Na}^{+}$ion also frequently visited the binding site (Figure 3B), in contrast to $\mathrm{Mg}^{2+}$, it could bind to both monomers simultaneously (Figure $\mathrm{S} 1$ ). In the holoenzyme simulations, in which both ions were present, $\mathrm{Mg}^{2+}$ occupied the binding site considerably longer. Such inclination can be explained by the electrostatic potential distribution for the protein (Figure S4). The active site vicinity has a patch of negative charges, favoring the more positively charged $\mathrm{Mg}^{2+}$ ions. Nonetheless, our result indicates that the competition of $\mathrm{Na}^{+}$for the binding site reduces the access of $\mathrm{Mg}^{2+}$, especially when tRNA is present, in agreement with experimental data showing that $\operatorname{TrmD}$ is the most active in the absence of monovalent ions (e.g., $\mathrm{KCl}^{39}$ ).

In order to validate the identity of the $\mathrm{Mg}^{2+}$ binding site determined by the MD simulations, we measured the kinetics of methyl transfer $\left(k_{\text {obs }}\right)$ under single-turnover conditions as a function of $\mathrm{Mg}^{2+}$ concentration. This allowed us to determine both the enzyme affinity for the metal ion $\left[K_{\mathrm{d}}\left(\mathrm{Mg}^{2+}\right)\right]$ and the rate of the chemical step $\left(k_{\text {chem }}\right)$. While the wild type enzyme exhibited both $K_{\mathrm{d}}\left(\mathrm{Mg}^{2+}\right)$ and $k_{\text {chem }}$ closely similar to those reported previously (Figure $4 \mathrm{~A}),{ }^{40}$ the alanine substitution of each of the three carboxylic residues generated a mutant with either one or both of these parameters negatively affected (Figure 4B-D). Thus, the mutants displayed reduced overall catalytic efficacy of the methyl transfer in terms of $k_{\text {chem }} /$ $K_{\mathrm{d}}\left(\mathrm{Mg}^{2+}\right)$.

2.1.2. Crystal Structures Support the Location of $\mathrm{Mg}^{2+}$ Determined by MD Simulations. Although there are no $\mathrm{Mg}^{2+}$ ions explicitly identified in any of the available structures of TrmD, the possibility exists that because of the similarity in the electron density between $\mathrm{Mg}^{2+}$ (and $\mathrm{Na}^{+}$) ions and water molecules, some of the ions have been misinterpreted as crystal waters. There are in fact examples that $\mathrm{Mg}^{2+}$ and other ions have been incorrectly recognized as water and vice versa. ${ }^{41,42}$ Therefore, using the method that characterizes the number of interactions between water molecules and surrounding atoms $^{41}$ we investigated crystal waters in the available X-ray structures of TrmD.

We found water molecules interacting with more than four standard partners located in the active site in four of the structures. ${ }^{33,34}$ The location of the waters corresponds to that of $\mathrm{Mg}^{2+}$ and $\mathrm{Na}^{+}$established in our MD simulations (Figure $3 \mathrm{C}$, more information in the Supporting Information). In each case, the waters are in contact with SAM (or its analog) and the carboxylate groups of acidic residues, suggesting that in fact they might be metal ions. Moreover, the crystal structure of TrmD-tRNA-SFG (PDB code: 4yvi) contains an unassigned electron density near the methionine moiety of the ligand ${ }^{35}$ (Figure 3D). Its position corresponds almost exactly to the 

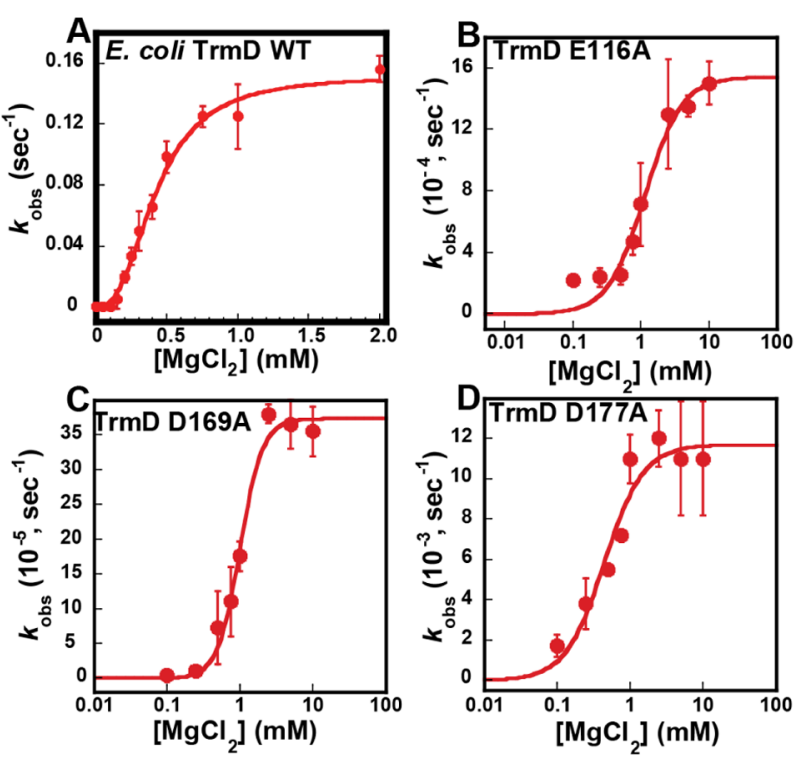

\begin{tabular}{|c|c|c|c|}
\hline & $\boldsymbol{k}_{\text {chem }}\left(\mathrm{sec}^{-1}\right)$ & $K_{\mathrm{d}}\left(\mathrm{Mg}^{2+}, \mathbf{m M}\right)$ & Fold Decrease \\
\hline WT & $\mathbf{0 . 1 6} \pm \mathbf{0 . 0 2}$ & $\mathbf{0 . 4 2} \pm \mathbf{0 . 0 2}$ & 1 \\
\hline E116A & $\mathbf{0 . 0 0 1 5} \pm \mathbf{0 . 0 0 0 1}$ & $\mathbf{1 . 1} \pm \mathbf{0 . 2}$ & $\mathbf{1 / 2 8 0}$ \\
\hline D169A & $\mathbf{0 . 0 0 0 4} \pm \mathbf{0 . 0 0 0 0 1}$ & $\mathbf{1 . 0} \pm \mathbf{0 . 3}$ & $\mathbf{1} / 950$ \\
\hline D177A & $\mathbf{0 . 0 1 1} \pm \mathbf{0 . 0 0 1}$ & $\mathbf{0 . 4 4} \pm \mathbf{0 . 0 7}$ & $1 / 15$ \\
\hline
\end{tabular}

Figure 4. Mutations in the negatively charged $\mathrm{Mg}^{2+}$-binding patch hinder the methyl transfer by TrmD. Shown are titrations of $k_{\mathrm{obs}} v s$ the metal ion concentration for (A) wild type TrmD enzyme, (B) E116A mutant, (C) D169A mutant, and (D) D177A mutant. Shown at the bottom are kinetic parameters $k_{\text {chem }}, K_{\mathrm{d}}\left(\mathrm{Mg}^{2+}\right)$, and the fold change of $k_{\text {chem }} / K_{\mathrm{d}}\left(\mathrm{Mg}^{2+}\right)$.

location of the waters identified by the above procedure as well as to the preferred $\mathrm{Mg}^{2+}$ binding site observed in the simulations. Hence, the crystal waters may be an overlooked metal ion bound to the enzyme.

All of these data support the results of the simulations and indicate the presence of a binding site for cations within the active site of TrmD, comprised of the carboxylates of E116, D169*, D177*, and SAM.

2.1.3. $\mathrm{Mg}^{2+}$ Binding Alters the Conformation of the Active Site. To assess how $\mathrm{Mg}^{2+}$ binding impacts the structure of TrmD, we performed 10 independent MD simulations of the ternary complex (jointly $1 \mu \mathrm{s}$ ) with $\mathrm{Mg}^{2+}$ placed from the start in the previously identified binding site. During these simulations, we observed no departure of the metal ion from the site, likely due to its strong electrostatic interactions with the negatively charged carboxylates.

The simulations showed that the presence of $\mathrm{Mg}^{2+}$ considerably alters the active site. Most notably, D169* moves away from G37 to a separation distance as long as $5.5 \AA$, allowing for a water molecule to come in between. To a lesser extent, R154* also moves away from the $\mathrm{O}^{6}$ of $\mathrm{G} 37$ and the methyl of SAM moves away from the $\mathrm{N}^{1}$ of G37 (Figure 5). Intriguingly, while these conformational changes render the key $\mathrm{R} 154^{*}$ and D169* residues to be distanced from the nucleobase substrate, as it will be shown by QM calculations (see below), they actually facilitate the methyl transfer.

The influence of $\mathrm{Mg}^{2+}$ binding extends beyond the alteration of the positions of the active site residues. Simulations of the binary complex of TrmD with SAM demonstrated that the ion is also crucial to induce the bent conformation of the methyl donor, a unique feature that is required for methyl transfer in the active site of $\mathrm{TrmD}^{12}$ and is distinct from the open

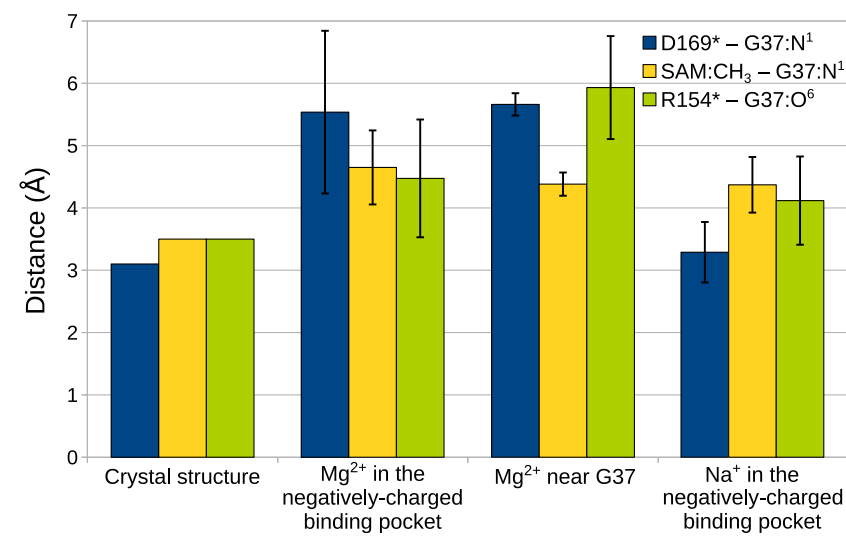

Figure 5. Important distances in the active site of TrmD depending on the presence and location of positive ions. Each distance is shown as an average minimal distance with standard deviation from at least 9 independent trajectories of tRNA-bound complexes or as a value extracted from the TrmD crystal structure (PDB code: $4 y v i$ ).

conformation present in Trm5. While, in the absence of tRNA, the methionine moiety of SAM is rather flexible in the active site, shifting between the open and the bent conformation, its coordination to $\mathrm{Mg}^{2+}$ through the carboxylate group stabilizes the bent structure. In contrast, this stabilization does not occur with $\mathrm{Na}^{+}$, which largely promoted the open conformation in the simulations (Figure 6). Thus, $\mathrm{Mg}^{2+}$ impacts the

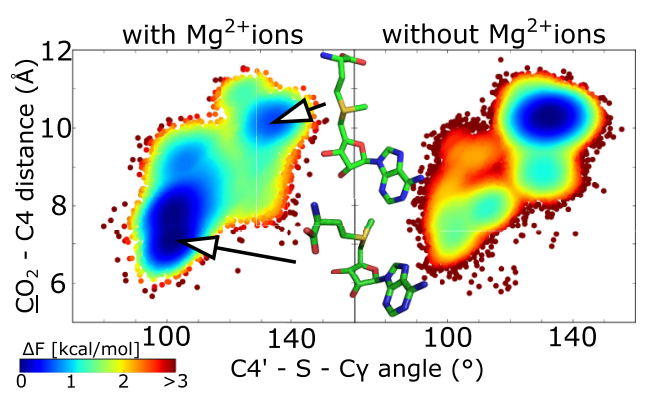

Figure 6. Free-energy landscape of SAM conformational space based on simulations of the holoenzyme with (left panel) and without (right panel) magnesium ions. Distance between the carboxylic carbon and C4 in SAM shows the separation between its methionine and adenine moieties, whereas the angle between $\mathrm{C} 4^{\prime}, \mathrm{S}$, and $\mathrm{C} \gamma$ indicates whether the ligand is in the bent $\left(\right.$ about $100^{\circ}$ ) or the extended (about $135^{\circ}$ ) conformation.

conformation of SAM in a way important for catalysis. Because of the shifts between the open and bent conformation, we tested whether $\mathrm{Mg}^{2+}$ binding alters the energy of SAM binding in these two states. We analyzed the network of hydrogen bonds in both open and bent states of SAM in TrmD (Table S3). This shows that the number of hydrogen bonds is approximately constant in the two states, consistent with a previous observation that $\mathrm{Mg}^{2+}$ binding does not affect the affinity of SAM for the enzyme. ${ }^{6}$ However, we observed different types of hydrogen bonds in the two states, reflecting the differences between them. For instance, the hydrogen bond between the amino group of the methionine moiety in SAM and the carboxylate of $\mathrm{D} 177^{*}$ is specific for the bent form, whereas it is substituted by a hydrogen bond between R154* and the carboxylate group of SAM in the open form. Thus, $\mathrm{Mg}^{2+}$ binding constrains the methyl donor into the bent conformation even before the binding of tRNA. 
2.1.4. Placing $\mathrm{Mg}^{2+}$ near $\mathrm{G} 37$ of $t R N A$. As described above, $\mathrm{Mg}^{2+}$ did not spontaneously bind to G37 during the simulations, and when manually placed in this location, it left the site shortly. However, when $\mathrm{Mg}^{2+}$ is temporarily present next to G37, the active site undergoes some conformational changes relative to the crystal structure. Specifically, D169* moves away from the nucleobase, such that the direct hydrogen bond with the $\mathrm{N}^{1}$ is broken (average distance 5.7 $\AA$, Figure 5) and replaced by a water bridge. This is similar to the situation observed in the case of $\mathrm{Mg}^{2+}$ bound in the negatively charged pocket. However, the conformation of R154* is drastically different for $\mathrm{Mg}^{2+}$ located near G37. Namely, the residue is extensively separated from the nucleobase because of the repulsion with the nearby positively charged ion.

2.1.5. $\mathrm{Na}^{+}$Does Not Alter the Active Site. During the simulations of both binary and ternary complexes of TrmD in the absence of $\mathrm{Mg}^{2+}$ ( $6 \mu \mathrm{s}$ in 15 independent trajectories), $\mathrm{Na}^{+}$ was found to bind in the same negatively charged binding pocket within the active site. However, $\mathrm{Na}^{+}$binding did not alter the conformations and interactions of key amino acids (Figure 5). D169* maintained a direct contact with $\mathrm{N}^{1}$ of G37 (via a hydrogen bond, average distance $3.3 \AA$ ), and R154* maintained a direct contact with the $\mathrm{O}^{6}$ of $\mathrm{G} 37$ (via a hydrogen bond, average distance $4.1 \AA$ ). Also, unlike $\mathrm{Mg}^{2+}$, the coordination of $\mathrm{Na}^{+}$did not enhance the bent conformation of SAM (Figure 6). These observations indicate that the structural positions of key residues do not align for catalysis in the presence of $\mathrm{Na}^{+}$, in contrast to the situation when $\mathrm{Mg}^{2+}$ is bound as described above.

2.2. QM Calculations. Having characterized the binding of $\mathrm{Mg}^{2+}$ (and $\mathrm{Na}^{+}$) to TrmD by MD simulations, we set out to determine how the presence of the metal ion influences the methyl transfer reaction. We used QM calculations based on the density functional theory (DFT), which allows for a direct evaluation of bond-breaking and bond-forming events. In particular, we applied the cluster approach, which is an accurate and reliable method to model enzymatic reactions at a reasonable computational cost ${ }^{43-46}$ and has been applied to investigate a number of SAM-dependent methyl transfer reactions. ${ }^{47-49}$ DFT functional B3LYP with D3 dispersion correction was used in the computations (see the Methods section for technical details). Using this methodology, we calculated the energy profiles for the methyl transfer with: (1) a $\mathrm{Mg}^{2+}$ ion located in the negatively charged binding pocket within the active site identified by the MD simulations (Figure 3A), (2) a $\mathrm{Mg}^{2+}$ ion positioned next to G37, (3) two $\mathrm{Mg}^{2+}$ ions occupying both positions simultaneously, and (4) a $\mathrm{Na}^{+}$ion bound instead of $\mathrm{Mg}^{2+}$ (Figure 3B).

The assembly of a proper active site model of $\operatorname{TrmD}$ for the cluster approach presented a major challenge. This is because for a given position of $\mathrm{Mg}^{2+}$ (or $\mathrm{Na}^{+}$), the active site still displayed a substantial conformational flexibility in the simulations. To account for as much structural diversity as possible, we constructed models for QM calculations by extensive sampling of MD trajectories and by manually selecting snapshots representing different conformational clusters of the active site. We then computed the energy profiles of the methyl transfer for each of these models. Although this approach cannot ensure finding the lowest energy pathway possible, it should allow for screening the bulk of the conformational space and for obtaining an estimate of the energy barrier for a given location of the metal ion. In total,
15 models were evaluated, consisting of $182-287$ atoms. All of these models included the reaction substrates, SAM and G37, the metal ion(s), the two catalytic amino acids R154* and D169*, accompanied by relevant surrounding residues. Below, we present only models displaying the lowest calculated energy barrier for each of the examined positions of the metal ion, while showing others in the Supporting Information.

Based on previous mutational, structural, and kinetic studies of $\operatorname{TrmD},{ }^{6,12,35}$ the reaction mechanism consists of two chemical steps, (1) a proton transfer from the $\mathrm{N}^{1}$ of G37 to D169* and (2) a methyl transfer from SAM to $\mathrm{N}^{1}$ (Figure 7).

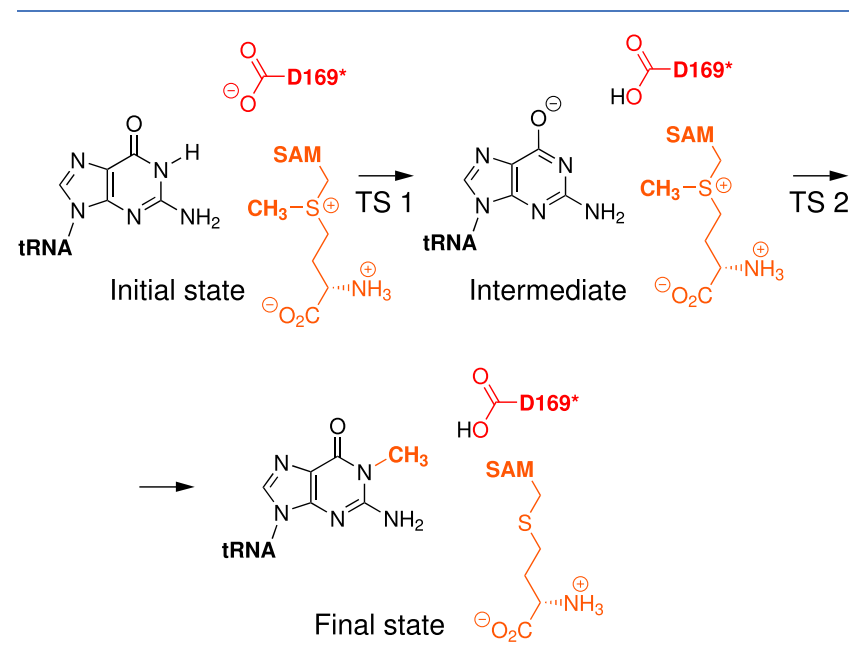

Figure 7. Overview of a general mechanism of the methylation of G37 by $\mathrm{TrmD}$, which consists of two chemical steps, the proton transfer from $\mathrm{N}^{1}$ to $\mathrm{D} 169^{*}$ and the methyl transfer from SAM to $\mathrm{N}^{1}$.

Therefore, only this order of events was considered in QM calculations. The experimental rate constant $\left(k_{\text {chem }}\right)$ for the TrmD-catalyzed reaction in the presence of $\mathrm{Mg}^{2+}$ is $0.138 \mathrm{~s}^{-1}$, corresponding to an overall energy barrier of $19.4 \mathrm{kcal} / \mathrm{mol}$. This value provides a framework to evaluate the calculated barriers associated with the rate-determining step. As an additional verification, we used the results of the metal-rescue experiments. These have shown that the methyl transfer reaction to the thio-containing $S^{6}$-G37 analog of tRNA is four times slower (corresponding to about $1 \mathrm{kcal} / \mathrm{mol}$ higher barrier), but the activity of the enzyme can be restored to the original level by replacing $\mathrm{Mg}^{2+}$ ions in the reaction media with $\mathrm{Co}^{2+}$. On the other hand, the regular $\mathrm{O}^{6}-\mathrm{G} 37$ substrate is not methylated in the presence of $\mathrm{Co}^{2+}$ ions. ${ }^{6}$ To validate each model, we thus additionally calculated the energy barriers for the methyl transfer to the $\mathrm{S}^{6}-\mathrm{G} 37$ with both $\mathrm{Mg}^{2+}$ and $\mathrm{Co}^{2+}$ ions in the respective locations, as well as for the methylation of the unmodified $\mathrm{G} 37$ in the $\mathrm{Co}^{2+}$-containing active sites.

2.2.1. $\mathrm{Mg}^{2+}$ in the Negatively Charged Binding Pocket. $\mathrm{MD}$ simulations showed that $\mathrm{Mg}^{2+}$ preferentially binds to the negatively charged pocket in the active site, consisting of the carboxylates of E116, D169*, D177*, and SAM (Figure 3A). We selected 8 different snapshots from MD simulations for this location of the metal ion and used them to construct the active site models for QM calculations.

The most energetically favorable model (in terms of the barrier height) consisted of 9 amino acids (P58, G59, E116, V137, L138, T139, R154*, D169*, D177*), SAM, G37, and five water molecules (194 atoms in total). In the starting configuration, $\mathrm{Mg}^{2+}$ is coordinated by oxygen atoms of the 

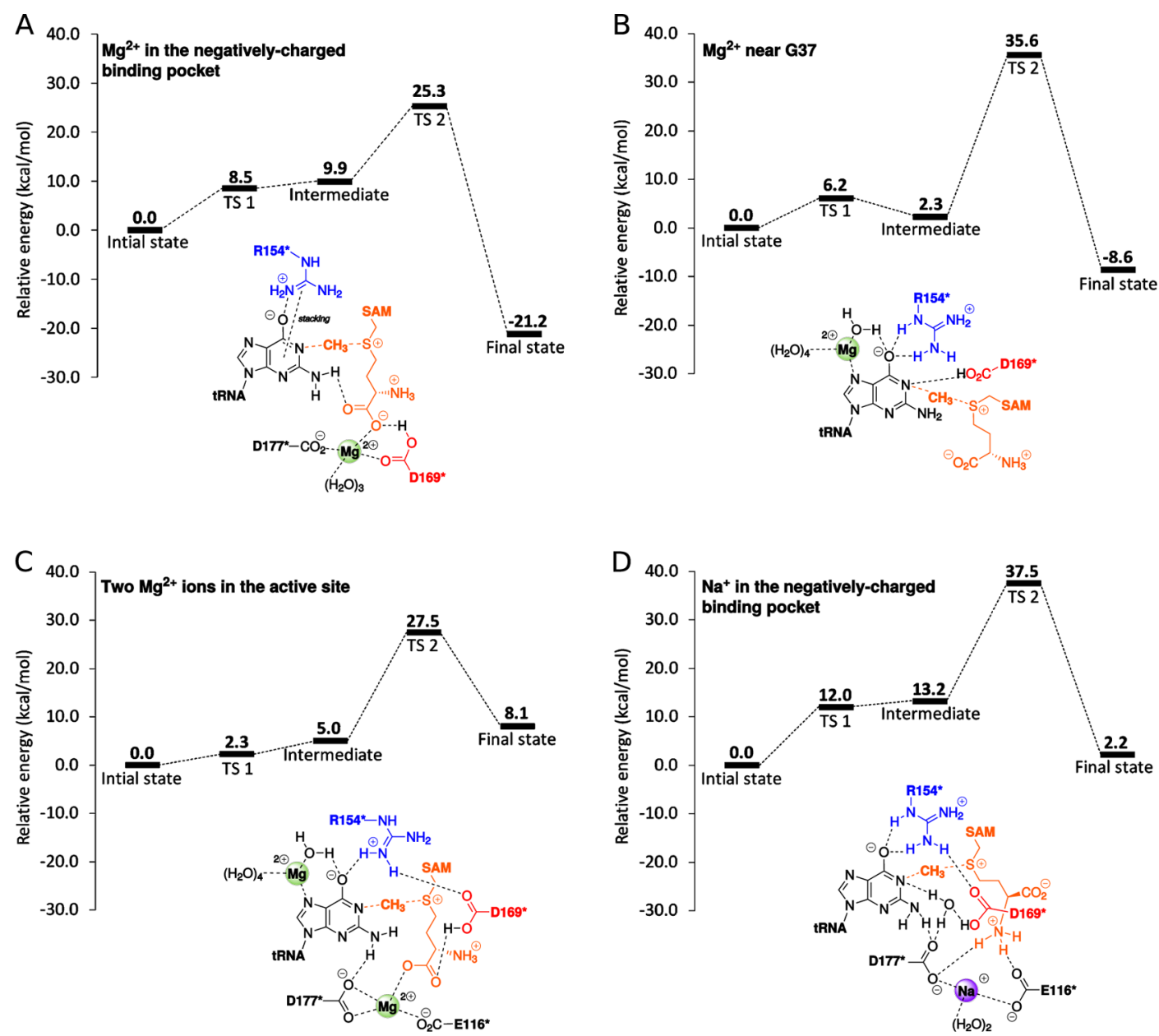

Figure 8. Energy profiles for methyl transfer reaction depending on the location of metal ions (the lowest-barrier model for each location is shown). The insets show schematic structures of TS 2. Note that after the inclusion of the ZPE correction in three cases the energy of intermediate becomes higher than that of TS 1 (see Figures S7-S10 for the decomposition of the respective energy contributions). TS: transition state.

carboxylates of D169*, D177*, and SAM, and three water molecules in an arrangement that was maintained throughout the reaction steps. In this model, D169* interacts with the $\mathrm{N}^{1}$ proton of G37 across a bridging water molecule (Figure S10).

The calculated energy barrier for proton transfer from the $\mathrm{N}^{1}$ of $\mathrm{G} 37$ to the carboxylate of D169* is $8.5 \mathrm{kcal} / \mathrm{mol}$ (TS1, Figure $8 \mathrm{~A}$ ). The resulting intermediate structure is an energy minimum in the optimization, which after zero-point energy (ZPE) corrections rises about $1 \mathrm{kcal} / \mathrm{mol}$ above the preceding transition state (see Figure S7 for details). After the proton transfer, the protonated D169* moves away from G37 to form a hydrogen bond with the carboxylate group of SAM. The negative charge developed at the $\mathrm{O}^{6}$ is stabilized by $\mathrm{R} 154^{*}$, which directly interacts with the nucleobase via hydrogen bonding and stacking at this stage. The intermediate is further stabilized by a hydrogen bond between the $\mathrm{N}^{2}$ and SAM's carboxylate.

In the subsequent transition state (TS 2), the methyl group is located exactly in between the sulfur of SAM and the nitrogen acceptor (Figure 9), approaching nearly in the plane of the nucleobase $\left(\mathrm{S}-\mathrm{CH}_{3}-\mathrm{N}^{1}\right.$ angle equals $\left.170^{\circ}\right)$. The methyl transfer is clearly the most difficult step of the mechanism, constituting the upper bound of the overall barrier of $25.3 \mathrm{kcal} / \mathrm{mol}$ (Figure 8). Although this is almost $6.0 \mathrm{kcal} /$ mol more than the experimental value, however, it can be considered admissible, given the inherent inaccuracy of the

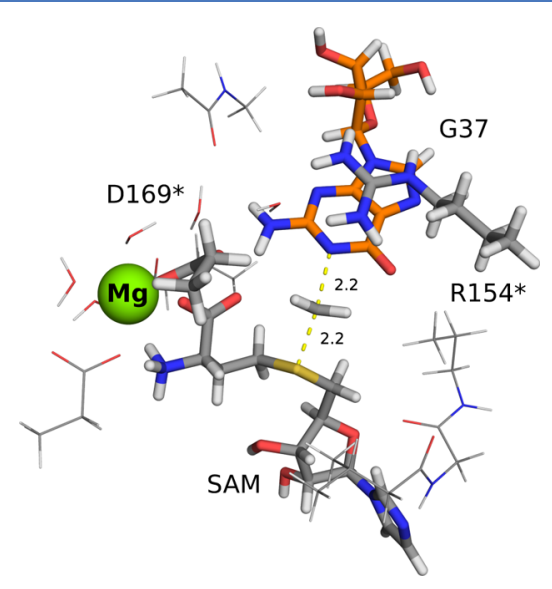

Figure 9. Optimized structure of the transition state for the methyl transfer (TS 2) with $\mathrm{Mg}^{2+}$ located in the negatively charged binding pocket (the position determined by the MD simulations). The key residues are shown with sticks. $\mathrm{Mg}^{2+}$ interacts with E116, D169*, D177*, SAM's carboxyl group and water molecules. Yellow dotted lines represent the distance (in $\AA$ ) from the transferring methyl group to the sulfur atom of SAM and to the $\mathrm{N}^{1}$ of G37.

underlying electronic structure method and the introduced modelistic approximations. A strong support for this location of $\mathrm{Mg}^{2+}$ is provided by the calculations on the metal-rescue 
experiments. Namely, the height of the barrier increases by 2.0 $\mathrm{kcal} / \mathrm{mol}$ for the methyl transfer to the $\mathrm{S}^{6}-\mathrm{G} 37$, but lowers back upon replacing $\mathrm{Mg}^{2+}$ with $\mathrm{Co}^{2+}$ in the model (Table 1 , entry

Table 1. Calculated Values of the Overall Energy Barriers (kcal/mol) for the Methyl Transfer to Wild Type and $S^{6}$ G37 Depending on the Location and Identity of the Metal Ion

\begin{tabular}{cccccc} 
& \multicolumn{1}{c}{ metal ion } & WT & & & WT \\
entry & $\quad$ location & $\mathrm{Mg}^{2+}$ & $\mathrm{Sg}^{6}-\mathrm{G} 37$ & $\mathrm{~S}^{6}-\mathrm{G} 37$ & $\mathrm{G} 37$ \\
$\mathrm{Co}^{2+}$ & $\mathrm{Co}^{2+}$ \\
\hline $\begin{array}{c}\text { the negatively charged } \\
\text { pocket }\end{array}$ & 25.3 & 27.3 & 25.6 & 29.5 \\
2 & near G37 & 35.6 & 36.9 & 36.0 & 35.2 \\
3 & both positions & 27.5 & 25.9 & 25.0 & 30.7 \\
\hline
\end{tabular}

1). Moreover, the $\mathrm{Co}^{2+}$-containing active site has a prohibitory high barrier for the methylation of the unmodified substrate $(29.5 \mathrm{kcal} / \mathrm{mol})$. Therefore, the results of the metal rescue experiments are perfectly reproduced, although there is no direct contact between the metal and the $\mathrm{O}^{6}$ atom of G37.

2.2.2. $\mathrm{Mg}^{2+}$ near G37. In the MD simulations $\mathrm{Mg}^{2+}$ did not spontaneously interact with G37, and when it was manually placed in this location, the ion departed from it within $10 \mathrm{~ns}$ (see above). However, it is still conceivable that the visits of $\mathrm{Mg}^{2+}$ to this site are very rare, thus missed even by long simulations, but its transient presence is sufficient to affect the catalysis. Therefore, we evaluated the methyl transfer reaction with $\mathrm{Mg}^{2+}$ located near G37. Because of limited MD data, we were able to construct just two structurally different models of this type. The one with the lowest overall energy barrier included 11 amino acids (V21, P58, G59, Y115, E116, G117, V137, L138, T139, R154*, L160*, D169*), SAM, G37, and 6 water molecules (208 atoms in total). Throughout the reaction steps, $\mathrm{Mg}^{2+}$ ion was coordinated to the $\mathrm{N}^{7}$ of $\mathrm{G} 37$ in a solvation shell of five water molecules, one of which is hydrogen-bonded to the $\mathrm{O}^{6}$.

The calculated energy barrier for the deprotonation of the $\mathrm{N}^{1}$ by $\mathrm{D} 169^{*}$ is $6.2 \mathrm{kcal} / \mathrm{mol}$ and the resulting intermediate is only $2.3 \mathrm{kcal} / \mathrm{mol}$ higher in energy relative to the initial state. After the deprotonation, the $\mathrm{O}^{6}$ of $\mathrm{G} 37$ moves into a direct contact with R154*, and forms hydrogen bonds with two of the water molecules that coordinate $\mathrm{Mg}^{2+}$ (Figure S11). Therefore indeed, as postulated previously (see Figure 1 and accompanying text), the direct interaction of $\mathrm{Mg}^{2+}$ with G37, renders the proton transfer very facile and provides substantial stabilization of the anionic intermediate.

During the subsequent methyl transfer step, the methyl group approaches nearly in the plane of the nucleobase (Figure 10; $\mathrm{S}-\mathrm{CH}_{3}-\mathrm{N}^{1}$ angle equals $173^{\circ}$ ), while the $\mathrm{S}-\mathrm{CH}_{3}$ distance is quite long $(2.7 \AA)$, indicating a late transition state. The calculated overall barrier for the reaction is, however, as high as $35.6 \mathrm{kcal} / \mathrm{mol}$ (Figure $8 \mathrm{~B}$ ), significantly more than the experimental value. Such an outcome may be due to the highly unstable nature of the transition state, which was proposed to involve a nonplanar 8 -membered ring, where a $\mathrm{Mg}^{2+}$ is the last member to join. ${ }^{6}$

However, until further experimental data, this model is not considered, because of the high barrier combined with the scarcity of $\mathrm{Mg}^{2+}$ visits to this location. Also, the calculated barrier heights for the metal-rescue experiments with the metal ion positioned near G37 (Table 1, entry 2) do not agree with

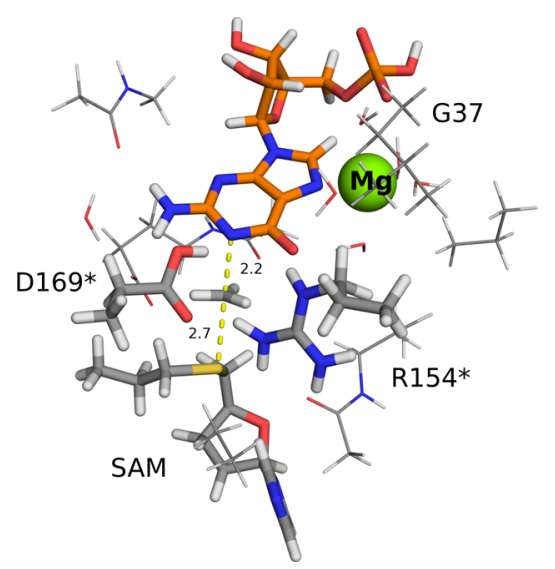

Figure 10. Optimized structure of the transition state for the methyl transfer (TS 2) with $\mathrm{Mg}^{2+}$ located near G37. The key residues are shown with sticks. $\mathrm{Mg}^{2+}$ interacts with the $\mathrm{N}^{7}$ of $\mathrm{G} 37$ and water molecules. Yellow dotted lines represent distances as in Figure 9.

the trends observed experimentally (the lowest barrier for the methylation of WT G37 in the presence of $\left.\mathrm{Co}^{2+}\right){ }^{6}$

2.2.3. Two $\mathrm{Mg}^{2+}$ lons. Although such a situation did not occur in the MD simulations, for completeness and to gain additional insight, we examined the methyl transfer with two $\mathrm{Mg}^{2+}$ ions present in the two active sites at the same timeone coordinated by the carboxylates of the negatively charged binding pocket and the other located near G37. Therefore, additional simulations were performed, based on which models of this type were constructed. The best one consists of 14 amino acids (V21, G57, P58, G59, Y115, E116, G117, V137*, L138*, T139*, R154*, E168*, D169*, D177*), SAM, G37, and seven water molecules (254 atoms in total). Throughout the reaction steps, the $\mathrm{Mg}^{2+}$ ion located near G37 is coordinated with the $\mathrm{N}^{7}$ and five water molecules, whereas the $\mathrm{Mg}^{2+}$ coordinated in the negatively charged patch has an additional contact with the carbonyl group of E168* (Figure S12).

The calculated energy barrier for the deprotonation step is $2.3 \mathrm{kcal} / \mathrm{mol}$ and the resulting intermediate is $5.0 \mathrm{kcal} / \mathrm{mol}$ relative to the starting point after the inclusion of the ZPE correction (Figure S9). During methyl transfer, R154* forms a hydrogen bond with the $\mathrm{O}^{6}$, and the methyl group approaches the nucleobase almost in its plane $\left(\mathrm{S}-\mathrm{CH}_{3}-\mathrm{N}^{1}\right.$ angle equals $\left.174^{\circ}\right)$. The distance between the methyl group and the $\mathrm{N}^{1}$ is shorter than that between the methyl group and the sulfur $(2.1$ vs $2.4 \AA$, Figure 11). The overall energy barrier for the methyl transfer is calculated to be $27.5 \mathrm{kcal} / \mathrm{mol}$ (Figure $8 \mathrm{C}$ ).

Therefore, the binding of $\mathrm{Mg}^{2+}$ in the negatively charged pocket seems to be the key to furnishing the catalytically competent active site geometry. The slightly higher barrier (by $2.2 \mathrm{kcal} / \mathrm{mol}$ ) than the one obtained with just one $\mathrm{Mg}^{2+}$ bound in this position most likely originates from the overstabilization of the intermediate by the additional metal ion present next to G37.

However, this model does not reproduce the results of the metal-rescue experiments, as the energy barrier calculated for the $\mathrm{Mg}^{2+}$-catalyzed methyl transfer to $\mathrm{S}^{6}$-G37 is lower than to the WT G37 (Table 1, entry 3). Hence, based on the results of the QM calculations, the mechanistic pathway with two $\mathrm{Mg}^{2+}$ ions present simultaneously in the active site is unlikely, consistent with biochemical data. ${ }^{6}$ 


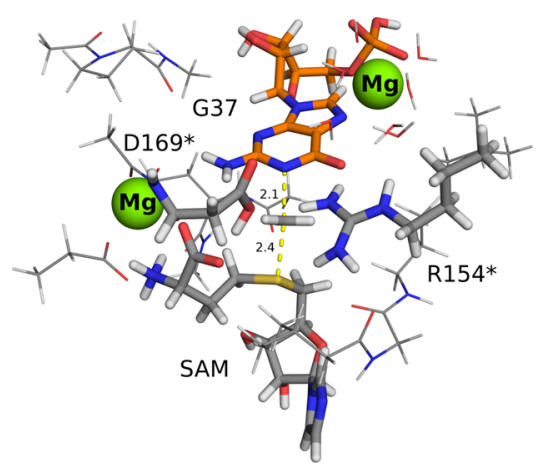

Figure 11. Optimized structure of the transition state for the methyl transfer (TS 2) with two $\mathrm{Mg}^{2+}$ located in the active site, one coordinated with $\mathrm{N}^{7}$ and five water molecules, while the other one with E116, D169*, D177*, SAM, and E168*. The key residues are shown with sticks. Yellow dotted lines represent distances as in Figure 9.

2.2.4. $\mathrm{Na}^{+}$in the Negatively Charged Binding Pocket. $\mathrm{MD}$ simulations showed that $\mathrm{Na}^{+}$spontaneously enters the active site in the same negatively charged patch as $\mathrm{Mg}^{2+}$. Two models containing $\mathrm{Na}^{+}$ion were constructed and the more energetically favorable one is comprised of 12 amino acids (E116, V137, L138, T139, R154*, S165*, A166*, E167*, E168*, D169*, S170*, D177*), SAM, G37, and five water molecules (212 atoms in total).

In this model, $\mathrm{Na}^{+}$is coordinated by the carboxylates of E116 and D177*, and also by the carbonyl of E168*, along with two water molecules (Figure S13). However, $\mathrm{Na}^{+}$does not coordinate with the carboxylate of SAM, as the latter is turned toward SAM's ribose moiety. Also, the two catalytic residues $\mathrm{R} 154^{*}$ and $\mathrm{D} 169^{*}$ interact via a salt bridge. Additionally, R154* forms hydrogen bonds with $\mathrm{O}^{6}$ and D169*. In turn, D169* interacts indirectly with the $\mathrm{N}^{1}$ proton of G37 via a bridging water molecule. The observed configuration was maintained throughout the two reaction steps.

In the first step, the $\mathrm{N}^{1}$ proton is abstracted by a water molecule and is transferred to D169* with an energy barrier of $12.0 \mathrm{kcal} / \mathrm{mol}$. The resulting intermediate, after $\mathrm{ZPE}$ corrections, exhibits higher energy $(13.2 \mathrm{kcal} / \mathrm{mol})$ compared to the preceding state (Figure S10). In the methyl transfer step, the methyl group is positioned in the middle between the sulfur of SAM and the $\mathrm{N}^{1}$ of G37 (2.3 and $2.2 \AA$, respectively), and is almost in the plane of the nucleobase $\left(\mathrm{S}-\mathrm{CH}_{3}-\mathrm{N}^{1}\right.$ angle equals $167^{\circ}$, Figure 12). The calculated overall energy barrier for the methyl transfer is $37.5 \mathrm{kcal} / \mathrm{mol}$ (Figure 8).

Therefore, although $\mathrm{Na}^{+}$is located in the active site in the same position as $\mathrm{Mg}^{2+}$, the high barrier obtained for the $\mathrm{Na}^{+}$ position indicates that the monovalent ion does not have the capacity to induce a catalytically competent conformation of the active site.

2.3. Summary. The MD simulations clearly identified a preferred binding pocket for the $\mathrm{Mg}^{2+}$ ion within the active site of TrmD. This binding pocket is made up of negatively charged carboxylates of E116, D169*, D177*, and SAM, which coordinate the metal ion. The location of this binding site and its importance for catalysis are corroborated by mutational studies and an extensive analysis of the available crystal structures of $\mathrm{TrmD}$. In the $\mathrm{MD}$ simulations, $\mathrm{Mg}^{2+}$ spontaneously enters the binding site from the solution. Importantly, while there are two such sites in the dimeric enzyme, only a

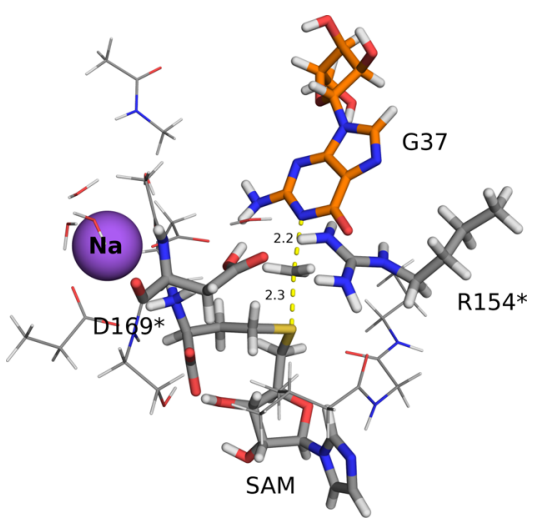

Figure 12. Optimized structure of the transition state for the methyl transfer (TS 2) with $\mathrm{Na}^{+}$located in the negatively charged binding pocket. Residues crucial for the reaction are shown with sticks. Yellow dotted lines represent distances as in Figure 9.

single $\mathrm{Mg}^{2+}$ ion binds indiscriminately to one of them at a time, in line with the experimental observations. The pocket is also capable of binding $\mathrm{Na}^{+}$ions, however, with a lower affinity.

Upon the binding of $\mathrm{Mg}^{2+}$ in the negatively charged pocket, the active site undergoes a structural reorganization. Most notably, by coordinating to the carboxylate of SAM, $\mathrm{Mg}^{2+}$ enforces the methyl donor to adapt the bent conformation, which has been shown to be required for the methyl transfer by the trefoil-knot fold. ${ }^{12}$ The presence of $\mathrm{Mg}^{2+}$ causes also conformational changes to the active site residues, as evidenced by, but not limited to, increased distances of $\mathrm{R} 154^{*}$ and D169* to G37 nucleobase relative to these seen in the crystal structure. Conversely, the binding of $\mathrm{Na}^{+}$in the pocket does not promote the bent conformation of SAM (although it is still accessible) and leaves the overall geometry of the active site largely unchanged compared to the crystal structure.

The $\mathrm{QM}$ calculations show that $\mathrm{Mg}^{2+}$ binding in the negatively charged pocket of the active site is necessary for the catalysis, as the presence of the metal ion only in this particular location leads to a plausible energy barrier for the methyl transfer reaction. The role of the metal ion seems to be organizing the active site residues within the topological knotfold in a geometry optimal for catalysis as that occurs in silico during the $\mathrm{MD}$ simulation stage. Although there is no direct interaction between $\mathrm{Mg}^{2+}$ and $\mathrm{G} 37$, which could assist the $\mathrm{N}^{1}$ deprotonation electronically, the coordination of the ion to D169* positions the latter perfectly for the abstraction of the proton. The negative charge developing at the $\mathrm{O}^{6}$ atom in the course of the deprotonation is just sufficiently stabilized by R154*. The sulfonium moiety of SAM is also ideally oriented for the subsequent methyl transfer step. Importantly, the effect of $\mathrm{Mg}^{2+}$ presence in the negatively charged pocket is not limited to these key residues, but it subtly affects the arrangement of all the active site components, which collectively lower the energy barrier.

The results of the previous metal-rescue experiments could also be accurately reproduced by the QM modeling of the active site containing the metal ion bound in the negatively charged pocket.

\section{CONCLUSIONS}

TrmD is a $\mathrm{Mg}^{2+}$-dependent methyltransferase responsible for the synthesis of $\mathrm{m}^{1} \mathrm{G} 37$-tRNA required for reading-frame 
maintenance during protein synthesis in bacteria. ${ }^{8,10}$ While $\operatorname{TrmD}$ is a high-priority antibacterial target, the lack of information on its utilization of $\mathrm{Mg}^{2+}$ for catalysis presents obstacles for developing strategies to target the enzyme.

Using a combined approach of MD simulations and QM calculations, we suggested the binding site for $\mathrm{Mg}^{2+}$ and uncovered its catalytic potential. In the MD simulations, $\mathrm{Mg}^{2+}$ preferentially binds to the active site of the enzyme within a negatively charged pocket and induces conformational changes to both catalytic amino acid residues and the SAM methyl donor. QM calculations prove that only in the geometry obtained upon $\mathrm{Mg}^{2+}$ binding, the active site becomes catalytically competent. These results were additionally validated by experimental mutational studies, which demonstrated the importance of the $\mathrm{Mg}^{2+}$-binding residues for the catalytic activity. Therefore, our studies reveal a new therapeutically relevant location within the active site of the knotted bacterial methyltransferase TrmD, which is unrelated to unknotted eukaryotic methyltransferase Trm5.

This work is also important from the methodological viewpoint. It provides and validates a strategy, which integrates the strengths and rigors of both $\mathrm{MD}$ simulations and $\mathrm{QM}$ calculations, to study $\mathrm{Mg}^{2+}$-dependent reactions, wherein the difficulty to spectroscopically study the metal ion often obscures insights into the catalytic mechanism.

\section{METHODS}

4.1. MDs Simulations. Atomistic MDs simulations with explicit water (TIP3P model) were performed in GROMACS 5.0.2 software package with the CHARMM36 force field. The crystal structure of TrmD in complex with SAM (PDB code: luak) and TrmD in complex with tRNA and SFG (PDB code: 4yvi; the $\mathrm{CH}-\mathrm{NH}_{2}$ moiety of SFG was replaced with $\mathrm{S}-\mathrm{CH}_{3}$, keeping the coordinates of the respective heavy atoms) were used as the starting configurations. Simulations were conducted using the same methodology as described before, ${ }^{12}$ where the system was protonated in $\mathrm{pH} 8.0$ using the PDB2PQR server. ${ }^{50}$ The systems were neutralized with the addition of appropriate amounts of $\mathrm{Na}^{+}$ions and in the simulation with $\mathrm{Mg}^{2+}$ ions present we applied also $6 \mathrm{mM}$ $\mathrm{MgCl}_{2}$, which correspond to the concentration used in the experimental study on TrmD. ${ }^{6}$ Specifically, $3 \mathrm{Mg}^{2+}$ and $12 \mathrm{Na}^{+}$ ions were added to the TrmD-SAM complex, and $7 \mathrm{Mg}^{2+}$ and $31 \mathrm{Na}^{+}$to the TrmD-SAM-tRNA complex. Force field CHARMM36 has necessary parameters for the ligand (SAM) and also reproduces correctly the octahedral coordination of the magnesium ions. The constraint algorithm LINCS is applied, which allows for calculations with 2 fs time step. Minimization of the energy of the systems was performed with the steepest descent minimization algorithm until the force was less than $0.01 \mathrm{~kJ} / \mathrm{mol} / \mathrm{nm}$. The equilibration of the solvent with constrained solution (with force constant $1000 \mathrm{~kJ} / \mathrm{mol}$ $\mathrm{nm}^{2}$ ) was carried out in constant temperature $310 \mathrm{~K}$ for 250 ps. The whole system equilibration in constant temperature and pressure were done for additional 250 ps. The NoseHoover thermostat and Parrinello-Rahman barostat were used. Electrostatic and van der Waals interactions were cut at the length of $12 \AA$. The coordinates were saved every 10 ps.

Free-energy landscape analysis was performed based on the conformations of SAM in the holoenzyme simulations. Specifically, in order to distinguish between the open and bent conformation, we used the distance between the adenine and methionine moiety ( $\mathrm{C} 4$ and $\mathrm{CO}_{2}$, respectively) and the angle between $\mathrm{C}^{\prime}-\mathrm{S}-\mathrm{C} \gamma$. The energy in each protein state $\left(\mathrm{s}_{i}\right)$ was based on the probability of being in this state $\left(P\left(\mathrm{~s}_{i}\right)\right)$

$$
\Delta F=-k T \ln \left(\frac{P\left(s_{i}\right)}{P_{\max }(s)}\right)
$$

The number of H-bonds was computed using g_hbond program from GROMACS package using a $3.2 \AA$ cut-off for the distance between the donor and acceptor and a cutoff for $50^{\circ}$ for the $X-H-Y$ angle. The interactions were calculated for every 100 ps of the trajectory.

4.1.1. Replica Exchange MD Simulations. Each replica was prepared based on the PDB code: 4yvi and equilibrated separately, following the same procedure as in classical MD simulations. The simulations were run either in temperature range from 305 to $320 \mathrm{~K}$ (23 replicas) or from 320 to $335 \mathrm{~K}$ (22 replicas). The appropriate temperature for each replica was calculated $^{51}$ with exchange probability set to 0.2 . The production run of each replica was performed for $50 \mathrm{~ns}$.

4.2. Quantum Chemical Calculations. All calculations were carried out using Gaussian 09 package. The active site models were based on snapshots from MDs simulations. Geometry optimizations were performed with B3LYP functional $^{52-56}$ including DFT-D3 dispersion correction, ${ }^{57,58}$ and $6-31 G(d, p)$ basis set (LANL2DZ for $\left.\mathrm{Co}^{59}\right)$. Coordinates of selected atoms were fixed during geometry optimizations to prevent unrealistic movements of residues. At the same level of theory, frequency calculations were performed to obtain ZPE corrections and single-point CPCM solvation ${ }^{60,61}$ energies were calculated (with $\epsilon=4$ ) to model the effects of the rest of the enzyme. To obtain more accurate energies, single-point calculations with B3LYP-D3 and $6-311+\mathrm{G}(2 \mathrm{~d}, 2 \mathrm{p})$ basis set (LANL2TZ(f) for $\mathrm{Co}^{59}$ ) were performed on the optimized geometries. The final energies reported are those for the large basis set corrected for ZPE and solvation effects.

\section{ASSOCIATED CONTENT}

\section{Supporting Information}

The Supporting Information is available free of charge at https://pubs.acs.org/doi/10.1021/acscatal.0c00059.

Frequency of ions occurrence in the negatively charged pocket in the active site; type and duration of MD simulations; water molecules in TrmD crystal structures; electrostatic potential on the TrmD structure; RMSD of SAM and the number of hydrogen bonds between SAM and protein; detailed energies for the quantum models; and optimized structures of the stationary points (PDF)

\section{AUTHOR INFORMATION}

\section{Corresponding Authors}

Marcin Kalek - Centre of New Technologies, University of Warsaw, Warsaw 02-097, Poland; 이이.org/0000-00021595-9818; Email: m.kalek@cent.uw.edu.pl

Ya-Ming Hou - Department of Biochemistry and Molecular Biology, Thomas Jefferson University, Philadelphia, Pennsylvania 19107, United States; 이이.org/0000-00016546-2597; Email: ya-ming.hou@jefferson.edu

Joanna I. Sulkowska - Centre of New Technologies and Faculty of Chemistry, University of Warsaw, Warsaw 02-097, Poland; 이 orcid.org/0000-0003-2452-0724; Email: jsulkowska@ cent.uw.edu.pl 


\section{Authors}

Agata P. Perlinska - Centre of New Technologies and College of Inter-Faculty Individual Studies in Mathematics and Natural Sciences, University of Warsaw, Warsaw 02-097, Poland; (1) orcid.org/0000-0003-2806-1190

Thomas Christian - Department of Biochemistry and Molecular Biology, Thomas Jefferson University, Philadelphia, Pennsylvania 19107, United States

Complete contact information is available at: https://pubs.acs.org/10.1021/acscatal.0c00059

\section{Notes}

The authors declare no competing financial interest.

\section{ACKNOWLEDGMENTS}

This work was supported by EMBO Installation Grant 2057 (to J.I.S.), the Polish Ministry for Science and Higher Education 0003/ID3/2016/64 (to J.I.S.), and by NIH R01 grants GM126210 and AI139202 (to Y.-M.H.). This research was carried out with the support of the Interdisciplinary Centre for Mathematical and Computational Modelling (ICM) at University of Warsaw under grants no G65-5, GA65-25, and GB70-7 and in part with the support of PLGrid Infrastructure.

\section{REFERENCES}

(1) Bist, P.; Rao, D. N. Identification and mutational analysis of $\mathrm{Mg}^{2+}$ binding site in EcoP15I DNA methyltransferase: involvement in target base eversion. J. Biol. Chem. 2003, 278, 41837-41848.

(2) Ferrer, J.-L.; Zubieta, C.; Dixon, R. A.; Noel, J. P. Crystal structures of alfalfa caffeoyl coenzyme A 3-O-methyltransferase. Plant Physiol. 2005, 137, 1009-1017.

(3) Lukačin, R.; Matern, U.; Specker, S.; Vogt, T. Cations modulate the substrate specificity of bifunctional class IO-methyltransferase from Ammi majus. FEBS Lett. 2004, 577, 367-370.

(4) Kopycki, J. G.; Rauh, D.; Chumanevich, A. A.; Neumann, P.; Vogt, T.; Stubbs, M. T. Biochemical and structural analysis of substrate promiscuity in plant $\mathrm{Mg}^{2+}$-dependent $\mathrm{O}$-methyltransferases. J. Mol. Biol. 2008, 378, 154-164.

(5) Matte, A.; Tari, L. W.; Delbaere, L. T. How do kinases transfer phosphoryl groups? Structure 1998, 6, 413-419.

(6) Sakaguchi, R.; Lahoud, G.; Christian, T.; Gamper, H.; Hou, Y.M. A divalent metal ion-dependent N1-methyl transfer to G37-tRNA. Chem. Biol. 2014, 21, 1351-1360.

(7) Bjork, G. R.; Jacobsson, K.; Nilsson, K.; Johansson, M. J.; Byström, A. S.; Persson, O. P. A primordial tRNA modification required for the evolution of life? EMBO J. 2001, 20, 231-239.

(8) Gamper, H. B.; Masuda, I.; Frenkel-Morgenstern, M.; Hou, Y.$\mathrm{M}$. Maintenance of protein synthesis reading frame by EF-P and $\mathrm{m}^{1}$ G37-tRNA. Nat. Commun. 2015, 6, 7226.

(9) Gamper, H.; Masuda, I.; Frenkel-Morgenstern, M.; Hou, Y.-M. The UGG isoacceptor of tRNAPro is naturally prone to frameshifts. Int. J. Mol. Sci. 2015, 16, 14866-14883.

(10) Masuda, I.; Matsubara, R.; Christian, T.; Rojas, E. R.; Yadavalli, S. S.; Zhang, L.; Goulian, M.; Foster, L. J.; Huang, K. C.; Hou, Y.-M. tRNA methylation is a global determinant of bacterial multi-drug resistance. Cell Syst. 2019, 8, 302-314.

(11) Motorin, Y.; Helm, M. RNA nucleotide methylation. Wiley Interdiscip. Rev.: RNA 2011, 2, 611-631.

(12) Christian, T.; Sakaguchi, R.; Perlinska, A. P.; Lahoud, G.; Ito, T.; Taylor, E. A.; Yokoyama, S.; Sulkowska, J. I.; Hou, Y.-M. Methyl transfer by substrate signaling from a knotted protein fold. Nat. Struct. Mol. Biol. 2016, 23, 941.

(13) Tkaczuk, K. L.; Dunin-Horkawicz, S.; Purta, E.; Bujnicki, J. M. Structural and evolutionary bioinformatics of the SPOUT superfamily of methyltransferases. BMC Bioinf. 2007, 8, 73.
(14) Jamroz, M.; Niemyska, W.; Rawdon, E. J.; Stasiak, A.; Millett, K. C.; Sułkowski, P.; Sulkowska, J. I. KnotProt: a database of proteins with knots and slipknots. Nucleic Acids Res. 2014, 43, D306-D314.

(15) Goto-Ito, S.; Ito, T.; Ishii, R.; Muto, Y.; Bessho, Y.; Yokoyama, S. Crystal structure of archaeal tRNA (m1G37) methyltransferase aTrm5. Proteins: Struct., Funct., Bioinf. 2008, 72, 1274-1289.

(16) Goto-Ito, S.; Ito, T.; Kuratani, M.; Bessho, Y.; Yokoyama, S. Tertiary structure checkpoint at anticodon loop modification in tRNA functional maturation. Nat. Struct. Mol. Biol. 2009, 16, 1109.

(17) Christian, T.; Evilia, C.; Williams, S.; Hou, Y.-M. Distinct origins of tRNA ( $\left.{ }^{1} \mathrm{G} 37\right)$ methyltransferase. J. Mol. Biol. 2004, 339, 707-719.

(18) Lahoud, G.; Goto-Ito, S.; Yoshida, K.-i.; Ito, T.; Yokoyama, S.; Hou, Y.-M. Differentiating analogous tRNA methyltransferases by fragments of the methyl donor. RNA 2011, 17, 1236-1246.

(19) Perlinska, A. P.; Stasiulewicz, A.; Nawrocka, E. K.; Kazimierczuk, K.; Setny, P.; Sulkowska, J. I. Restriction of Sadenosylmethionine conformational freedom by knotted protein binding sites. PLoS Comput. Biol. 2020, 16, 1007904.

(20) Christian, T.; Hou, Y.-M. Distinct determinants of tRNA recognition by the TrmD and Trm5 methyl transferases. J. Mol. Biol. 2007, 373, 623-632.

(21) Sakaguchi, R.; Giessing, A.; Dai, Q.; Lahoud, G.; Liutkeviciute, Z.; Klimasauskas, S.; Piccirilli, J.; Kirpekar, F.; Hou, Y.-M. Recognition of guanosine by dissimilar tRNA methyltransferases. RNA 2012, 18, $1687-1701$

(22) White, T. A.; Kell, D. B. Comparative genomic assessment of novel broad-spectrum targets for antibacterial drugs. Comp. Funct. Genomics 2004, 5, 304-327.

(23) Gall, A. R.; Datsenko, K. A.; Figueroa-Bossi, N.; Bossi, L.; Masuda, I.; Hou, Y.-M.; Csonka, L. N. $\mathrm{Mg}^{2+}$ regulates transcription of mgtA in Salmonella Typhimurium via translation of proline codons during synthesis of the MgtL peptide. Proc. Natl. Acad. Sci. U.S.A. 2016, 113, 15096.

(24) Tacconelli, E.; Carrara, E.; Savoldi, A.; Harbarth, S.; Mendelson, M.; Monnet, D. L.; Pulcini, C.; Kahlmeter, G.; Kluytmans, J.; Carmeli, Y.; Ouellette, M.; Outterson, K.; Patel, J.; Cavaleri, M.; Cox, E. M.; Houchens, C. R.; Grayson, M. L.; Hansen, P.; Singh, N.; Theuretzbacher, U.; Magrini, N.; Aboderin, A. O.; AlAbri, S. S.; Awang Jalil, N.; Benzonana, N.; Bhattacharya, S.; Brink, A. J.; Burkert, F. R.; Cars, O.; Cornaglia, G.; Dyar, O. J.; Friedrich, A. W.; Gales, A. C.; Gandra, S.; Giske, C. G.; Goff, D. A.; Goossens, H.; Gottlieb, T.; Guzman Blanco, M.; Hryniewicz, W.; Kattula, D.; Jinks, T.; Kanj, S. S.; Kerr, L.; Kieny, M.-P.; Kim, Y. S.; Kozlov, R. S.; Labarca, J.; Laxminarayan, R.; Leder, K.; Leibovici, L.; Levy-Hara, G.; Littman, J.; Malhotra-Kumar, S.; Manchanda, V.; Moja, L.; Ndoye, B.; Pan, A.; Paterson, D. L.; Paul, M.; Qiu, H.; Ramon-Pardo, P.; Rodríguez-Baño, J.; Sanguinetti, M.; Sengupta, S.; Sharland, M.; SiMehand, M.; Silver, L. L.; Song, W.; Steinbakk, M.; Thomsen, J.; Thwaites, G. E.; van der Meer, J. W.; Van Kinh, N.; Vega, S.; Villegas, M. V.; Wechsler-Fördös, A.; Wertheim, H. F. L.; Wesangula, E.; Woodford, N.; Yilmaz, F. O.; Zorzet, A. Discovery, research, and development of new antibiotics: the WHO priority list of antibioticresistant bacteria and tuberculosis. Lancet Infect. Dis. 2018, 18, 318327.

(25) Hill, P. J.; Abibi, A.; Albert, R.; Andrews, B.; Gagnon, M. M.; Gao, N.; Grebe, T.; Hajec, L. I.; Huang, J.; Livchak, S.; Lahiri, S. D.; McKinney, D. C.; Thresher, J.; Wang, H.; Olivier, N.; Buurman, E. T. Selective inhibitors of bacterial tRNA- $\left(\mathrm{N}^{1} \mathrm{G} 37\right)$ methyltransferase (TrmD) that demonstrate novel ordering of the lid domain. J. Med. Chem. 2013, 56, 7278-7288.

(26) Sulkowska, J. I.; Rawdon, E. J.; Millett, K. C.; Onuchic, J. N.; Stasiak, A. Conservation of complex knotting and slipknotting patterns in proteins. Proc. Natl. Acad. Sci. U.S.A. 2012, 109, E1715E1723.

(27) Rawdon, E. J.; Millett, K. C.; Sułkowska, J. I.; Stasiak, A. Knot localization in proteins. Biochem. Soc. Trans. 2013, 41, 538-541.

(28) Millett, K. C.; Rawdon, E. J.; Stasiak, A.; Sułkowska, J. I. Identifying knots in proteins. Biochem. Soc. Trans. 2013, 41, 533-537. 
(29) Sulkowska, J. I. On folding of entangled proteins: knots, lassos, links and $\theta$-curves. Curr. Opin. Struct. Biol. 2020, 60, 131-141.

(30) Xu, Y.; Li, S.; Yan, Z.; Luo, Z.; Ren, H.; Ge, B.; Huang, F.; Yue, $\mathrm{T}$. Stabilizing effect of inherent knots on proteins revealed by molecular dynamics simulations. Biophys. J. 2018, 115, 1681-1689.

(31) Xu, Y.; Li, S.; Yan, Z.; Ge, B.; Huang, F.; Yue, T. Revealing cooperation between knotted conformation and dimerization in protein stabilization by molecular dynamics simulations. J. Phys. Chem. Lett. 2019, 10, 5815-5822.

(32) Sriramoju, M. K.; Chen, Y.; Hsu, S.-T. D. Protein knots provide mechano-resilience to an AAA+ protease-mediated proteolysis with profound ATP energy expenses. Biochim. Biophys. Acta, Proteins Proteomics 2020, 1868, 140330.

(33) Ahn, H. J.; Kim, H.-W.; Yoon, H.-J.; Lee, B. I.; Suh, S. W.; Yang, J. K. Crystal structure of tRNA ( $\left.\mathrm{m}^{1} \mathrm{G} 37\right)$ methyltransferase: insights into tRNA recognition. EMBO J. 2003, 22, 2593-2603.

(34) Elkins, P. A.; Watts, J. M.; Zalacain, M.; van Thiel, A.; Vitazka, P. R.; Redlak, M.; Andraos-Selim, C.; Rastinejad, F.; Holmes, W. M. Insights into catalysis by a knotted TrmD tRNA methyltransferase. $J$. Mol. Biol. 2003, 333, 931-949.

(35) Ito, T.; Masuda, I.; Yoshida, K.-i.; Goto-Ito, S.; Sekine, S.-i.; Suh, S. W.; Hou, Y.-M.; Yokoyama, S. Structural basis for methyldonor-dependent and sequence-specific binding to tRNA substrates by knotted methyltransferase TrmD. Proc. Natl. Acad. Sci. U.S.A. 2015, 112, E4197-E4205.

(36) Frederiksen, J. K.; Li, N.-S.; Das, R.; Herschlag, D.; Piccirilli, J. A. Metal-ion rescue revisited: Biochemical detection of site-bound metal ions important for RNA folding. RNA 2012, 18, 1123-1141.

(37) Pyle, A. Metal ions in the structure and function of RNA. JBIC, J. Biol. Inorg. Chem. 2002, 7, 679-690.

(38) When this manuscript was in revision, a structure of a sinefungin-bound (SAM analog) TrmD from Pseudomonas aeruginosa containing manganese ions was published: Jaroensuk, J.; Wong, Y. H.; Zhong, W.; Liew, C. W.; Maenpuen, S.; Sahili, A. E.; Atichartpongkul, S.; Chionh, Y. H.; Nah, Q.; Thongdee, N.; McBee, M. E.; Prestwich, E. G.; DeMott, M. S.; Chaiyen, P.; Mongkolsuk, S.; Dedon, P. C.; Lescar, J.; Fuangthong, M. Crystal structure and catalytic mechanism of the essential $\mathrm{m}^{1} \mathrm{G} 37 \mathrm{tRNA}$ methyltransferase TrmD from Pseudomonas aeruginosa. RNA 2019, 25, 1481-1496. ; PDB code: 6jki. The position of the $\mathrm{Mn}^{2+}$ perfectly overlays with the binding site for $\mathrm{Mg}^{2+}$ that we identify in this work. This structure strongly supports our results and demonstrates the applicability of our approach to detect metal binding sites in proteins

(39) Brulé, H.; Elliott, M.; Redlak, M.; Zehner, Z. E.; Holmes, W. M. Isolation and characterization of the human tRNA- $\left(\mathrm{N}^{1} \mathrm{G} 37\right)$ methyltransferase (TRM5) and comparison to the Escherichia coli TrmD protein. Biochemistry 2004, 43, 9243-9255.

(40) Christian, T.; Lahoud, G.; Liu, C.; Hou, Y.-M. Control of catalytic cycle by a pair of analogous tRNA modification enzymes. $J$. Mol. Biol. 2010, 400, 204-217.

(41) Wang, Z.; Sapienza, P. J.; Abeysinghe, T.; Luzum, C.; Lee, A. L.; Finer-Moore, J. S.; Stroud, R. M.; Kohen, A. $\mathrm{Mg}^{2+}$ binds to the surface of thymidylate synthase and affects hydride transfer at the interior active site. J. Am. Chem. Soc. 2013, 135, 7583-7592.

(42) Leonarski, F.; D’Ascenzo, L.; Auffinger, P. $\mathrm{Mg}^{2+}$ ions: do they bind to nucleobase nitrogens? Nucleic Acids Res. 2017, 45, 987-1004.

(43) Himo, F. Recent trends in quantum chemical modeling of enzymatic reactions. J. Am. Chem. Soc. 2017, 139, 6780-6786.

(44) Siegbahn, P. E. M.; Himo, F. The quantum chemical cluster approach for modeling enzyme reactions. Wiley Interdiscip. Rev.: Comput. Mol. Sci. 2011, 1, 323-336.

(45) Siegbahn, P. E. M.; Himo, F. Recent developments of the quantum chemical cluster approach for modeling enzyme reactions. $J$. Biol. Inorg Chem. 2009, 14, 643-651.

(46) Himo, F. Quantum chemical modeling of enzyme active sites and reaction mechanisms. Theor. Chem. Acc. 2006, 116, 232-240.

(47) Georgieva, P.; Wu, Q.; McLeish, M. J.; Himo, F. The reaction mechanism of phenylethanolamine N-methyltransferase: a density functional theory study. Biochim. Biophys. Acta, Proteins Proteomics 2009, 1794, 1831-1837.

(48) Velichkova, P.; Himo, F. Theoretical study of the methyl transfer in guanidinoacetate methyltransferase. J. Phys. Chem. B 2006, $110,16-19$.

(49) Velichkova, P.; Himo, F. Methyl transfer in glycine Nmethyltransferase. A theoretical study. J. Phys. Chem. B 2005, 109, $8216-8219$.

(50) Dolinsky, T. J.; Nielsen, J. E.; McCammon, J. A.; Baker, N. A. PDB2PQR: an automated pipeline for the setup of PoissonBoltzmann electrostatics calculations. Nucleic Acids Res. 2004, 32, W665-W667.

(51) Patriksson, A.; van der Spoel, D. A temperature predictor for parallel tempering simulations. Phys. Chem. Chem. Phys. 2008, 10, 2073-2077.

(52) Lee, C.; Yang, W.; Parr, R. G. Development of the ColleSalvetti correlation-energy formula into a functional of the electron density. Phys. Rev. B: Condens. Matter Mater. Phys. 1988, 37, 785.

(53) Becke, A. D. Density-functional exchange-energy approximation with correct asymptotic behavior. Phys. Rev. A 1988, 38, 3098.

(54) Becke, A. D. Density-functional thermochemistry. I. The effect of the exchange-only gradient correction. J. Chem. Phys. 1992, 96, $2155-2160$

(55) Becke, A. D. Density-functional thermochemistry. II. The effect of the Perdew-Wang generalized-gradient correlation correction. J. Chem. Phys. 1992, 97, 9173-9177.

(56) Becke, A. D. A new mixing of Hartree-Fock and local densityfunctional theories. J. Chem. Phys. 1993, 98, 1372-1377.

(57) Grimme, S.; Antony, J.; Ehrlich, S.; Krieg, H. A consistent and accurate $\mathrm{ab}$ initio parametrization of density functional dispersion correction (DFT-D) for the 94 elements H-Pu. J. Chem. Phys. 2010, $132,154104$.

(58) Grimme, S.; Ehrlich, S.; Goerigk, L. Effect of the damping function in dispersion corrected density functional theory. J. Comput. Chem. 2011, 32, 1456-1465.

(59) Hay, P. J.; Wadt, W. R. Ab initio effective core potentials for molecular calculations. Potentials for $\mathrm{K}$ to $\mathrm{Au}$ including the outermost core orbitals. J. Chem. Phys. 1985, 82, 299-310.

(60) Barone, V.; Cossi, M. Quantum calculation of molecular energies and energy gradients in solution by a conductor solvent model. J. Phys. Chem. A 1998, 102, 1995-2001.

(61) Cossi, M.; Rega, N.; Scalmani, G.; Barone, V. Energies, structures, and electronic properties of molecules in solution with the C-PCM solvation model. J. Comput. Chem. 2003, 24, 669-681. 